\title{
Involvement of hyaluronidases in colorectal cancer
}

\author{
Helen Bouga', Isidoros Tsouros', Dimitrios Bounias², Dora Kyriakopoulou², Michael S Stavropoulos², \\ Nikoletta Papageorgakopoulou', Dimitrios A Theocharis ${ }^{3}$, Demitrios H Vynios ${ }^{1 *}$
}

\begin{abstract}
Background: Hyaluronidases belong to a class of enzymes that degrade, predominantly, hyaluronan. These enzymes are known to be involved in physiological and pathological processes, such as tumor growth, infiltration and angiogenesis, but their exact role in tumor promotion or suppression is not clear yet. Advanced colorectal cancer is associated with elevated amounts of hyaluronan of varying size. The aim of the present study was therefore to illuminate the importance of hyaluronidases in colon carcinoma progression.
\end{abstract}

Methods: The patients' samples (macroscopically normal and cancerous) were subjected to sequential extraction with PBS, $4 \mathrm{M} \mathrm{GdnHCl}$ and $4 \mathrm{M} \mathrm{GdnHCl}-1 \%$ Triton X-100. The presence of the various hyaluronidases in the extracts was examined by zymography and western blotting. Their expression was also examined by RT-PCR.

Results: Among hyaluronidases examined, Hyal-1, $-2,-3$ and $\mathrm{PH}-20$ were detected. Their activity was higher in cancerous samples. Hyal-1 and Hyal-2 were overexpressed in cancerous samples, especially in advanced stages of cancer. Both isoforms were mainly extracted with PBS. Hyal-3 was observed only in the third extract of advanced stages of cancer. PH-20 was abundant in all three extracts of all stages of cancer. The expression of only Hyal-1 and $\mathrm{PH}-20$ was verified by RT-PCR.

Conclusion: A high association of hyaluronidases in colorectal cancer was observed. Each hyaluronidase presented different tissue distribution, which indicated the implication of certain isoforms in certain cancer stages. The results provided new evidence on the mechanisms involved in the progression of colorectal cancer.

\section{Background}

Hyaluronan (HA) is a multifunctional high molecular mass (HMM) glycosaminoglycan responsible for the maintenance of the extracellular matrix (ECM) of connective tissue. It is a simple linear glycosaminoglycan (GAG) composed of repeating disaccharide units of Dglucuronic acid and N-acetyl-D-glucosamine: $[-\beta(1,4)$ GlcUA- $\beta(1,3)$-GlcNAc- $]_{n}$. It is normally produced by hyaluronan synthases (HAS1, HAS2, HAS3) at plasma membrane and degraded extracellularly by the action of plasma membrane hyaluronidases (Hyals) [1-3], endocytosed, transferred to lysosomes where it is fully degraded by the action of hyaluronidase, beta-glucuronidase and beta- $\mathrm{N}$-acetylglucosaminidase. Depending on the tissue source, HA usually consists of 2,000-25,000 disaccharide

\footnotetext{
* Correspondence: vynios@chemistry.upatras.gr

'Laboratory of Biochemistry, Department of Chemistry, University of Patras,

Patras, Greece

Full list of author information is available at the end of the article
}

units, giving rise to molecular mass ranging from $10^{6}$ to $10^{7} \mathrm{Da}[4,5]$. Its lower molecular mass (LMM) forms participate in a wide variety of biological functions. HMM-HA is indicative of healthy tissues, while LMMHA seems to promote angiogenesis and activate signaling pathways that are critical for cancer progression. The LMM fragments could be truncated products of the synthetic reaction, but could also be the result of hyaluronidase activity [6].

Due to its unique biophysical properties, HA contributes directly to tissue homeostasis, interacts with link proteins and proteoglycans (PGs) thus maintaining the structural integrity of extracellular and pericellular matrices, and its interaction with cell surface HA receptors mediates crucial influences of HA on cell behavior. Due to all of these functions, HA plays regulatory roles in basic cellular behavior, such as cell adhesion, cell migration, cell-cell recognition and cell differentiation $[7,8]$, and thus participates in many important processes 
of morphogenesis, tissue remodeling, inflammation and several types of diseases, such as tumor growth and atherosclerosis. Elevated extracellular amounts of HA and its partially catabolized oligomers are correlated with several types of malignancies potentially due to decoupled synthesis and degradation $[9,10]$.

Hyaluronidases (Hyals) are a class of enzymes that degrade, predominantly, HA, and at a slower rate chondroitin and chondroitin sulphate. Hyals are endoglycosidases that degrade the $\beta-\mathrm{N}$-acetyl-D-glucosaminidic linkages in HA chains [11]. In the human genome there are six known genes coding for hyaluronidase-like sequences, all having a high degree of homology, but with different tissue distribution, namely hHyal-1 through -4, PH-20/Spam-1 and pseudogene Phyal1, that is transcribed in the human genome but not translated. Human Hyal-1 and Hyal-2 are the two major Hyals for the degradation of HA in somatic tissues, hHyal-2 degrades high molecular mass $\mathrm{HA}$ to an approximately $20 \mathrm{kDa}$ product, whereas Hyal-1 can degrade high molecular mass HA to small oligomers, primarily to tetrasaccharides [12]. A product of the human hyal-4 gene, Hyal-4, based on preliminary studies, is also a chondroitinase with a predominant activity toward Ch and ChS. According to their $\mathrm{pH}$ activity profiles, they are divided in two categories; Hyal-1, Hyal-2 and Hyal-3 are active at acidic $\mathrm{pH}(\mathrm{pH} 3.0-4.0)$ and are considered as acidic Hyals [13], while PH-20 is a neutral active Hyal, as it is active at $\mathrm{pH}$ 5.0-8.0 [14].

Hyals are known to be involved in biological processes such as development and tumorigenesis [13,15]. Among the six mammalian Hyals, Hyal-1 is the major tumorderived Hyal and is expressed by a variety of tumor cells, confirmed with several methods (RT-PCR analysis, cDNA cloning, protein purification, immunoblotting and immunohistochemistry). In addition to Hyal-1, RTPCR analysis has revealed PH-20 expression in head and neck carcinoma, especially laryngeal carcinoma [16,17]. Hyals levels are also shown to be elevated in breast tumors and RT-PCR analysis has detected the expression of PH-20, Hyal-2 and Hyal-3 in breast cancer tissues $[18,19]$. These observations suggest that Hyals appear to be implicated in many carcinomas, however the exact role of Hyals in colon cancer remains under great concern.

Accumulating evidence has demonstrated that the production of HA is excessive in malignant cancers; increased HA serum levels and deposition in tumour tissue are often associated with malignant progression in colorectal cancer [20]. The purpose of this study was to examine the activity and expression of Hyals in tissue samples from patients with colorectal cancer and to identify different isoforms profile in different stages of cancer.

\section{Methods}

\section{Chemicals}

Phosphate buffer saline (PBS), phenylmethylsulfonyl fluoride (PMSF), Alcian blue and Coomassie Brilliant blue were obtained from Serva (Darmstadt, Germany). Hyaluronic acid, hyaluronidase (type I) from bovine testes, benzamidine hydrochloride, $\varepsilon$-amino-n-caproic acid, Triton X-100, N-ethylmaleimide (NEM) and ethylenediaminetetracetic acid disodium salt dihydrate $\left(\mathrm{Na}_{2} \mathrm{EDTA}\right)$ were obtained from Sigma. Mouse polyclonal antibodies against hyaluroglucosaminidase 1 (Hyal1), hyaluroglucosaminidase 3 (Hyal-3) and sperm adhesion molecule 1 ( $\mathrm{PH}-20 /$ Spam-1) were obtained from Abnova Corporation (Taiwan). RNA extraction kit (Nucleospin RNA II) was from Macherey-Nagel. PrimeScript $^{\mathrm{TM}}$ one step RT-PCR kit and 100 bp DNA ladder were obtained from TakaRa BIO INC. All other chemicals used throughout the study were of the highest available grade.

\section{Tissue source}

Macroscopically normal and cancerous tissues were obtained from 34 patients (8 females and 26 males, age range 45-90), who underwent surgical operation due to colorectal carcinoma at the Surgical Clinic of the General University Hospital of Patras, Greece. The patients included in the study were healthy until the time of diagnosis of colorectal cancer, without any other disease. Surgical procedures consisted of different types of colorectal resection. Two specimens were obtained from each patient, one from the center of the tumor and the other of similar weight from areas adjacent to the cancerous regions (macroscopically normal areas), and were stored at $-80^{\circ} \mathrm{C}$ for further biochemical examination. Clinical information was obtained after clinical and pathological diagnosis of the patients: sex, age, location of primary tumor, pathological differentiation, distant metastasis and radiation therapy (Table 1 ). The clinical stage of all tumors was completed according to TNM and AstlerColler $(\mathrm{A} / \mathrm{C})$ classification. The study design was approved by the Ethical Committee of the University Hospital of the University of Patras and informed consent was obtained from all patients before entry into the study.

\section{Extraction and Zymographic examination of Hyals}

Parts of macroscopically normal and cancerous tissues were used for the detection of Hyals. Each specimen was finely diced and the macromolecules contained were sequentially extracted for $3 \times 24$ h periods at $4^{\circ} \mathrm{C}$ in the dark with PBS (10 $\mathrm{mM}$ disodium phosphate, $0.14 \mathrm{M} \mathrm{NaCl}, \mathrm{pH} 7.4), 4 \mathrm{M} \mathrm{GdnHCl}-0.05 \mathrm{M}$ sodium acetate and $4 \mathrm{M} \mathrm{GdnHCl}-0.05 \mathrm{M}$ sodium acetate 
Table 1 Characteristics of patients with colon cancer

\begin{tabular}{|c|c|c|c|c|c|}
\hline Case no. & Age & Sex & Loc $^{1}$ & Hist. features $^{2}$ & $A / C$ stage $^{3}$ \\
\hline 1 & 59 & $M$ & $S$ & - & Tis \\
\hline 2 & 66 & M & C & - & Tis \\
\hline 3 & 61 & M & R & - & Tis \\
\hline 4 & 72 & $\mathrm{~F}$ & $\mathrm{~T}$ & Well & A \\
\hline 5 & 90 & M & $\mathrm{R}$ & Poor & B1 \\
\hline 6 & 76 & M & S & Med & B1 \\
\hline 7 & 56 & M & $\mathrm{R}$ & Med & B1 \\
\hline 8 & 54 & $\mathrm{~F}$ & S & Well & B1 \\
\hline 9 & 74 & $F$ & S & Med & B2 \\
\hline 10 & 73 & M & $D$ & Med & B2 \\
\hline 11 & 84 & $\mathrm{~F}$ & $\mathrm{D}$ & Med & B2 \\
\hline 12 & 81 & M & $\mathrm{R}$ & Poor & B2 \\
\hline 13 & 66 & M & C & Med & B2 \\
\hline 14 & 74 & M & S & Well & B2 \\
\hline 15 & 77 & M & S & Med & B2 \\
\hline 16 & 79 & M & C & Med & B2 \\
\hline 17 & 45 & M & $\mathrm{T}$ & Med & B2 \\
\hline 18 & 58 & M & S & Med & B2 \\
\hline 19 & 60 & F & $\mathrm{R}$ & Med & $\mathrm{C} 1$ \\
\hline 20 & 82 & $F$ & $\mathrm{R}$ & Med & C1 \\
\hline 21 & 65 & M & C & Med & C1 \\
\hline 22 & 59 & M & $\mathrm{R}$ & Med & $\mathrm{C} 1$ \\
\hline 23 & 68 & F & $\mathrm{R}$ & Med & $\mathrm{C} 1$ \\
\hline 24 & 78 & M & S & Med & $C 2$ \\
\hline 25 & 87 & M & $\mathrm{R}$ & Med & $C 2$ \\
\hline 26 & 71 & M & $\mathrm{R}$ & Med & $C 2$ \\
\hline 27 & 72 & M & $A$ & Poor & $C 2$ \\
\hline 28 & 57 & $M$ & $S$ & Med & $C 2$ \\
\hline 29 & 61 & $M$ & A & Med & $C 2$ \\
\hline 30 & 50 & $M$ & $\mathrm{R}$ & Med & $C 2$ \\
\hline 31 & 80 & $M$ & C & Med & $C 2$ \\
\hline 32 & 80 & F & A & Poor & $C 2$ \\
\hline 33 & 72 & $M$ & $S$ & Med & $D$ \\
\hline 34 & 75 & $M$ & $A$ & Poor & $D$ \\
\hline
\end{tabular}

The patients have been classified according to the stage of cancer.

'Location (of primary tumor); A: ascending colon; C: cecum; D: descending colon; R: rectum; S: sigmoid colon; T: transverse colon.

${ }^{2}$ Histological features (Grade of differentiation); well: well differentiated; mod: moderately well differentiated; poor: poorly differentiated.

${ }^{3} \mathrm{~A} / \mathrm{C}$ stage; Astler-Coller classification of tumors. - represents non cancerous samples (adenoma tissues).

- 1\% Triton X-100, using 10 vols of extraction buffer per $g$ of tissue [21]. This three-step extraction procedure was applied to permit the differential extraction of Hyals isoforms, since accumulated evidence suggests that they are present in either soluble or membranebound form $[11,12]$. A protease inhibitor cocktail was included containing $5 \mathrm{mM}$ benzamidine hydrochloride, $0.4 \mathrm{mM}$ phenylmethylsulfonyl fluoride, $10 \mathrm{mM} \mathrm{N}$ ethylmaleimide, $0.1 \mathrm{M} \varepsilon$-amino-n-caproic acid and 0.01 $\mathrm{M} \mathrm{Na} \mathrm{N}_{2}$ EDTA. Each one of the extracts was stored at $-20^{\circ} \mathrm{C}$ until use.
Hyaluronidase activity of the various extracts was examined using a HA zymography procedure, as described previously [22-24]. The samples were electrophoresed and at the end of the electrophoresis the gel was submerged in the suitable buffer $(0.15 \mathrm{M} \mathrm{NaCl}-0.1$ $\left.\mathrm{M} \mathrm{CH}_{3} \mathrm{COONa} \mathrm{pH} 3.7\right)$ and incubated at $37^{\circ} \mathrm{C}$ for $16 \mathrm{~h}$. Then the gel was stained sequentially with Alcian blue to stain undegraded HA and with Coomassie blue to overstain the Alcian blue stained HA and the non enzymic protein bands. The enzyme activity appeared as white bands in a dark blue background. Finally, semiquantification of the enzymatic units was achieved after scanning of the gel by a digital scanner.

\section{Western Blotting identification of Hyaluronidases}

The various extracts were subjected to SDS-PAGE (T: $10 \%$, C: $2.7 \%$ ) according to Laemmli [25], using denaturing conditions in the presence of $\beta$-mercaptoethanol. After electrophoresis, the gels were immersed in $0.15 \mathrm{M}$ iodoacetamide in $0.05 \mathrm{M}$ Tris- $\mathrm{HCl} \mathrm{pH} 8.3$ for $15 \mathrm{~min}$ at room temperature to block free $\beta$-mercaptoethanol. Thereafter, the protein bands were electrotransferred to nitrocellulose (Immobilon NC) membranes at constant current of $80 \mathrm{~mA}$ at $4^{\circ} \mathrm{C}$ for $20 \mathrm{~h}$ in $0.05 \mathrm{M}$ Tris- $\mathrm{HCl}$ $\mathrm{pH}$ 8.3. The membranes were washed with PBS containing $0.1 \%$ Tween 20 (PBS-T) and blocked with 5\% dry skimmed milk in PBS-T. They were then incubated with the respective polyclonal antibody (against either Hyal-1, Hyal-2, Hyal-3 or PH-20) in an appropriate dilution in PBS-T for $1 \mathrm{~h}$ at room temperature. After repeated washings with PBS- $T$, the membranes were incubated with second antibody (goat anti-mouse IgG) peroxidaseconjugated (1:5000) in PBS-T, for $1 \mathrm{~h}$ at room temperature and washed exhaustively with PBS-T. The immunoreacting bands were visualized by enhanced chemiluminescence method (ECL), according to the manufacturer's instructions and by exposure to Agfa Curix X-ray film.

\section{RNA extraction and RT-PCR analysis}

Colorectal specimens were pulverized in liquid nitrogen and subjected to total RNA extraction, using the Nucleospin extraction kit, as described by the manufacturer and treated with RNase-freeDNase to remove contaminating genomic DNA. Strand cDNA was synthesized from $40 \mathrm{ng}$ of total RNA in $50 \mu \mathrm{l}$ reaction components for one-step RT-PCR kit, according to the manufacturer's instructions. This reaction mixture contained in addition $1 \mu \mathrm{M}$ of the sense and antisense primers showed in Table 2. The amplification was performed in a GeneAmp 2400 thermal cycler (PerkinElmer Co.) and the reaction profile used for all primers sets was: $95^{\circ} \mathrm{C}$ for $10 \mathrm{~min}$ for the activation of DNA polymerase and then 25-35 cycles, depending on the 
Table 2 Sequences of oligonucleotide primers for RT-PCR analysis

\begin{tabular}{|c|c|c|}
\hline Primer & Sequence $\left(5^{\prime}-3^{\prime}\right.$ direction) & $\begin{array}{l}\text { Product length } \\
\text { (bp) }\end{array}$ \\
\hline $\begin{array}{c}\text { Hyal-1 } \\
\text { (forward) }\end{array}$ & CATATTGAGAACCTAATGCACTCTG & 208 \\
\hline $\begin{array}{l}\text { Hyal-1 } \\
\text { (reverse) }\end{array}$ & GGAATGAATGGTGTCTGCTGTGG & \\
\hline $\begin{array}{c}\text { Hyal-2 } \\
\text { (forward) }\end{array}$ & TTGTGAGCTTCCGTGTTCAG & 217 \\
\hline $\begin{array}{l}\text { Hyal-2 } \\
\text { (reverse) }\end{array}$ & GTCTCCGTGCTTGTGGTGTA & \\
\hline $\begin{array}{c}\mathrm{PH}-20 \\
\text { (forward) }\end{array}$ & GAGTTGTAAGGAGAAAGCTGAT & 194 \\
\hline $\begin{array}{l}\mathrm{PH}-20 \\
\text { (reverse) }\end{array}$ & TGGCTACAGAAGAAATGATAAGAAACA & \\
\hline $\begin{array}{c}\text { GAPDH } \\
\text { (forward) }\end{array}$ & TCAACGGATTTGGTCGTATTGGG & 270 \\
\hline $\begin{array}{l}\text { GAPDH } \\
\text { (reverse) }\end{array}$ & GACTCCACGACGTACTCAGC & \\
\hline
\end{tabular}

analysis, at $94^{\circ} \mathrm{C}$ for $30 \mathrm{~s}, 62^{\circ} \mathrm{C}$ for $1 \mathrm{~min}$, and $72^{\circ} \mathrm{C}$ for $10 \mathrm{~min}$ to finalize extension. The number of cycles was chosen so that reactions could be terminated during the linear phase of amplification. The reaction products were separated by electrophoresis in $2 \%(\mathrm{w} / \mathrm{v})$ agarose gels contained Gelstar Stain to visualize the amplified cDNA fragments under UV. The gels were then scanned and the bands were analyzed densitometrically. Quantitative differences between cDNA samples were normalized by including GAPDH in all experiments.

\section{Statistical analysis}

Statistically significant differences in the detection of Hyals between healthy, macroscopically normal and cancerous tissues, were executed by students' $t$-test, using the microcal origin software. Significance was determined at values of $\mathrm{P}<0.05$.

\section{Results}

\section{Hyaluronidase activity of tissue extracts in colon cancer}

The sequential extracts from the various specimens were subjected to hyaluronan zymography in acidic conditions. In the majority of samples one lysis band was observed corresponding to $72 \mathrm{kDa}$. In minor number of samples, bands of smaller molecular mass (20-40 kDa) were also identified (not shown). These samples were of advanced stages of cancer (stages B and C). Semi-quantitative analysis of the zymograms revealed increased hyaluronidase activity in cancerous PBS tissue extracts compared to the macroscopically normal PBS extracts (fig. 1A), in all anatomic sites examined (not shown). Both activities were significantly increased compared to intact, healthy tissues (fig. 1B).

Hyaluronidase activity was significantly elevated in cancerous specimens compared to macroscopically normal ones in all anatomic sites examined (fig. 2A). Especially in the case of sigmoid and cecum, an increase of about 80 and $100 \%$ was calculated, whereas the increase was much smaller in the other anatomic sites. In addition, hyaluronidase activity seemed to vary with the stage of cancer. The highest activity was observed at early stages (Tis/A), as well as at stage D of cancer and

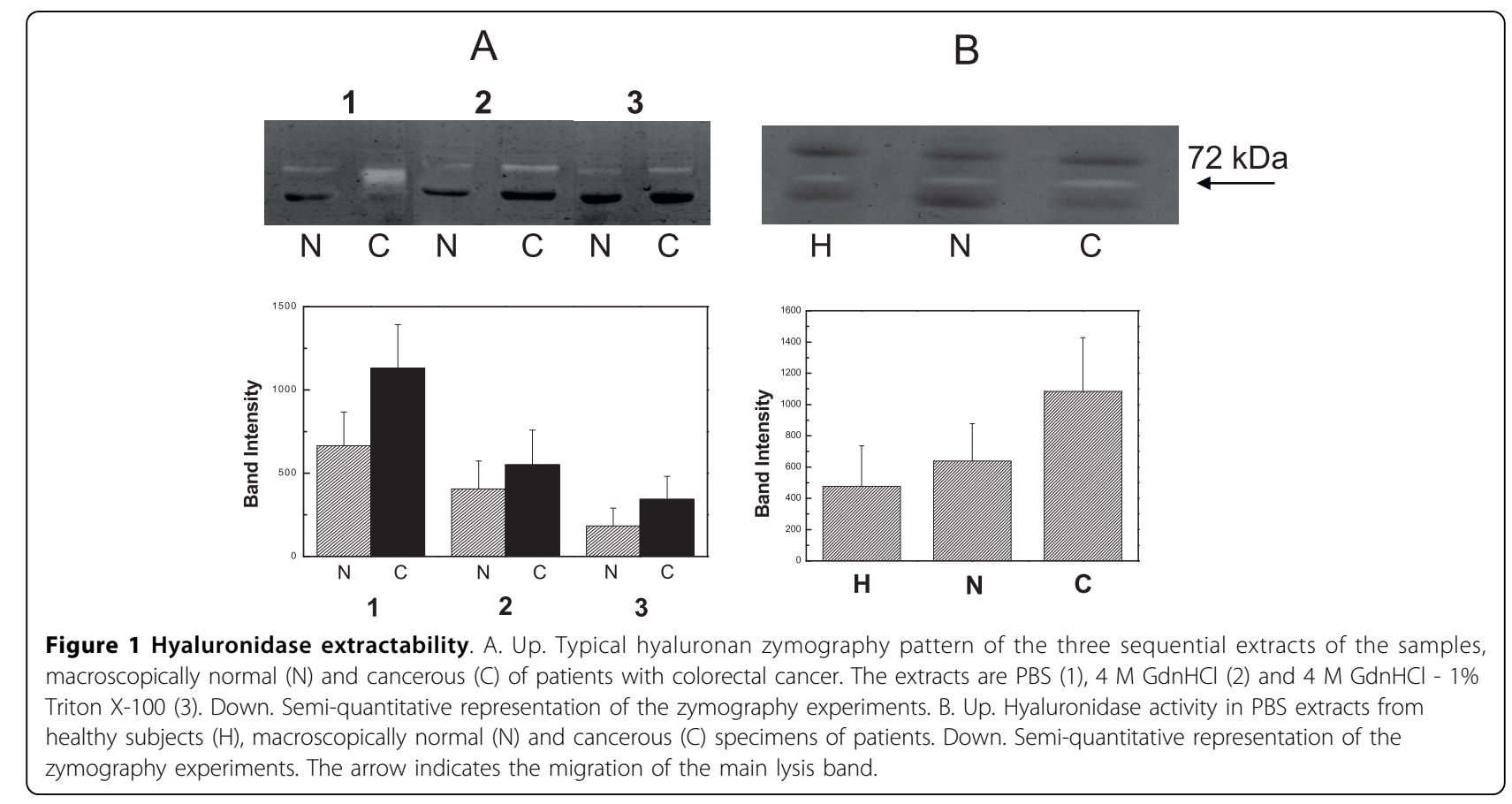




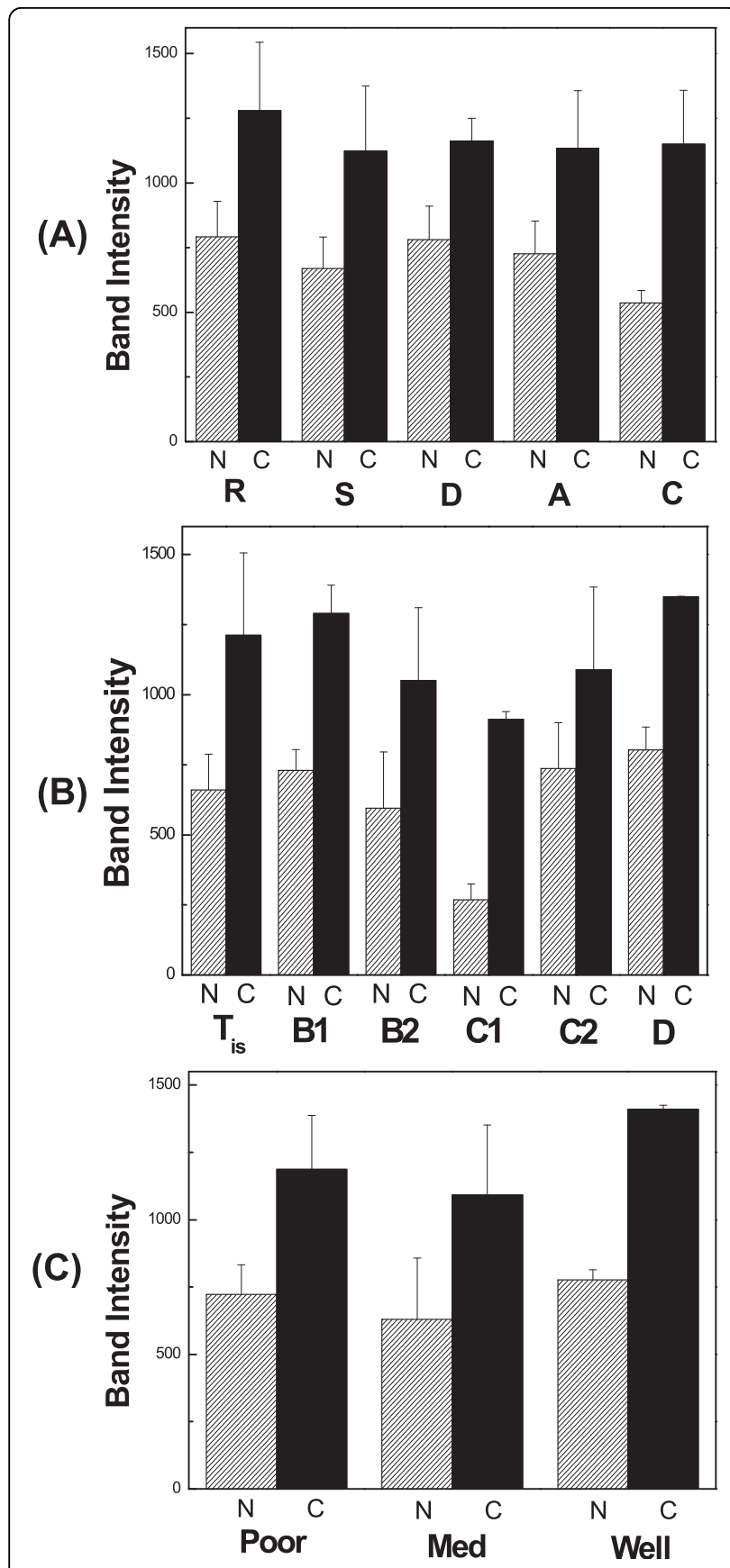

Figure 2 Quantification of hyaluronidase activity. Semiquantitative analysis of hyaluronidase in colon cancer after zymography of PBS extracts according to: (A) anatomic site, (B) stage of cancer, and (C) grade of cancer.

the lowest activity at. stage $\mathrm{C} 1$ (fig. 2B). Hyaluronidase activity was also related to the grade of cancer, being obvious in cancerous samples (fig. 2C), whereas the macroscopically normal samples seemed to contain about the same activity of the enzyme.

Western blotting analysis was further used for the identification of Hyal(s) present in the sequential extracts. In all tissue samples examined, Hyal-1, Hyal-2, Hyal-3 and $\mathrm{PH}-20$ were found to exist, each one observed in different extracts and different stages of cancer. Hyal-1 was overexpressed in cancerous samples than in macroscopically normal ones, mainly in advanced stages of cancer (fig. 3A). Hyal-2 was expressed, but not in large amounts, in tissue samples of patients with advanced stage (B and C) of cancer (fig. 3B). Both Hyal-1 and Hyal-2 were mainly, if not exclusively, extracted with PBS. On the other hand, Hyal-3 was observed only in $4 \mathrm{M}$ GdnHCl-1\% Triton X-100 extracts of advanced stages of cancer (fig. 3C). PH-20 was abundant in all three extracts of different stages of cancer; in PBS extracts PH-20 was detected mainly in cancerous samples (fig. 3D), but in $4 \mathrm{M} \mathrm{GdnHCl}$ and 4 M GdnHCl-1\% Triton X-100 extracts was mainly detected in macroscopically normal samples.

\section{RT-PCR analysis of hyaluronidase transcripts in colon cancers}

Hyaluronidases expression in tissue was also examined by RT-PCR analysis (fig. 4). The results indicated that Hyal-1 was overexpressed in cancerous samples compared to macroscopically normal ones. Semi-quantitative analysis of the results revealed increased Hyal-1 expression especially in $\mathrm{B} 2, \mathrm{C} 1$ and $\mathrm{C} 2$ stage of cancer (fig. 4A). PH-20 was overexpressed at early stages of cancer, especially in the cancerous samples; considerable expression was also observed in benign tumors (fig. 4B). Hyal2 and -3 expression at the mRNA levels was not identified at any of the samples examined. Additional examinations, regarding any mutations of the genes or alternative splicing of mRNA have not been performed.

\section{Discussion}

A large amount of studies shows that hyaluronan deposition is up-regulated in most malignancies. Especially in human cancers, hyaluronan concentrations are usually higher in cancerous than in normal tissues. Colon cancer, among other kinds of cancer, is considered to enriched with hyaluronan $[6,26]$. In that kind of tumor, hyaluronan may support tumor growth by stimulating anchorage-independent growth and proliferation of tumor cells. Moreover, hyaluronan may also actively promote tumor cell adhesion, migration and metastasis and may also protect against immune surveillance [27]. Additionally, tumor cells may take advantage of hyaluronan-rich extracellular matrices to invade more easily into the surrounding tissues.

Based on these observations, in this work we investigated the activity and the expression of hyaluronidases in tissue samples from patients with colon cancer, for clarifying the dependence of hyaluronan catabolism on individual hyaluronidase activities under pathological 

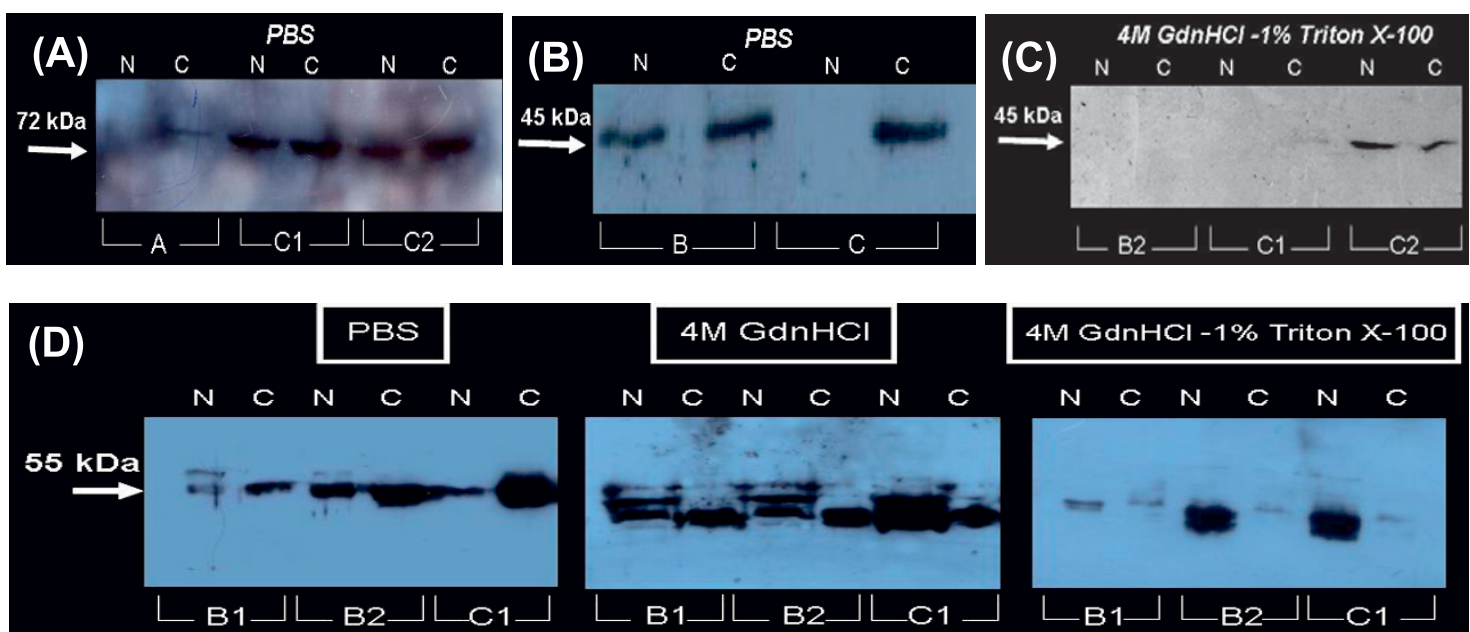

Figure 3 Western blotting analysis of hyaluronidases. A. Hyal-1 in macroscopically normal (N) and cancerous (C) PBS extracts of A, C1 and C2 stages of cancer. B. Hyal-2 in macroscopically normal (N) and cancerous (C) PBS extracts of B and C stages of cancer. C. Hyal-3 in macroscopically normal ( $\mathrm{N}$ ) and cancerous (C) 4 M GdnHCl-1\% Triton X-100 extracts of B2, C1 and C2 stages of cancer. D. PH-20 in macroscopically normal (N) and cancerous (C) samples of B2, C1 and C2 stages of cancer; left; PBS extracts, middle; 4 M GdnHCl extracts and right; $4 \mathrm{M} \mathrm{GdnHCl-1 \%}$ Triton X-100 extracts. The arrows indicate the migration of the main immunoreacting band.

conditions. It has been reported that hyaluronidases act as tumor inhibitors in vivo [28], Hyal-1 reversibly correlates with hyaluronan content [29] and that Hyal-1 correlates with tumor grade, stage, and multifocality $[17,30]$. The results of our study indicated that hyaluronidases were involved in colon cancer progression. Sequential extraction of hyaluronidases from the various specimens was applied in the study to obtain an idea on their localization, since PBS would extract enzyme isoforms freely available within the tissue, $4 \mathrm{M} \mathrm{GdnHCl}$ would extract enzyme isoforms entrapped in or interacted with macromolecular aggregates and Triton-X would extract membrane bound or intracellularly localized enzyme isoforms.

\section{A}
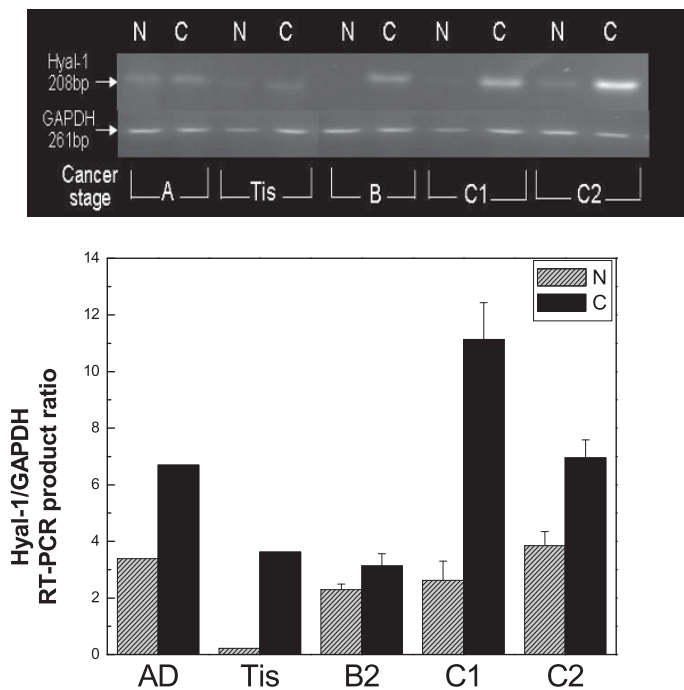

\section{B}
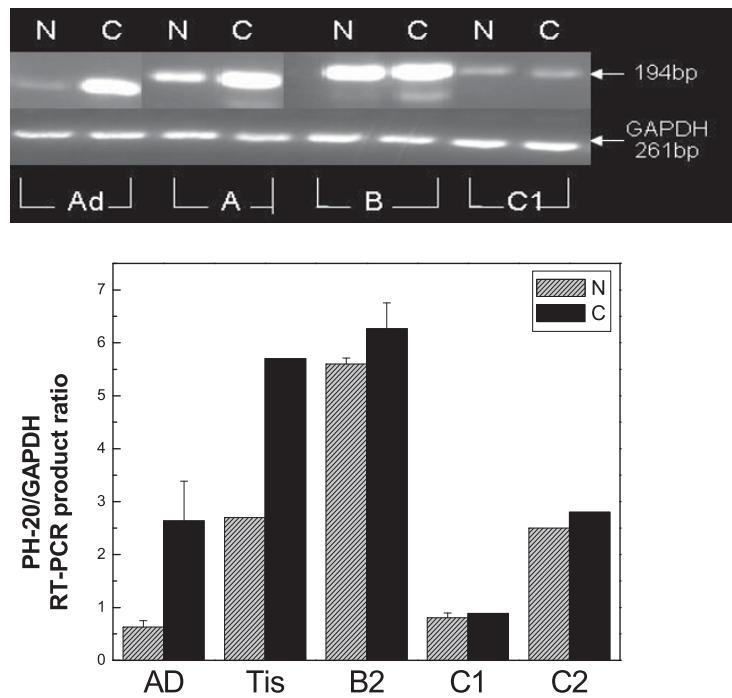

Figure 4 RT-PCR analysis of hyaluronidases. A. Up. CDNA product of Hyal-1 (208 bp) in macroscopically normal (N) and cancerous (C) samples from different patients. Down. Semi-quantitative representation of the results. B. Up. CDNA product of PH-20 (194 bp) in macroscopically normal (N) and cancerous (C) samples from different patients. Down. Semi-quantitative representation of the results. The arrows indicate the migration of CDNA products of GAPDH and hyaluronidases. 
At first, much more activity of hyaluronidase was observed in PBS extracts, compared to $4 \mathrm{M} \mathrm{GdnHCl}$ and $4 \mathrm{M} \mathrm{GdnHCl}-1 \%$ Triton X-100 extracts. About 50\% of the enzyme activity was extracted with PBS from the macroscopically normal specimens, and more than $60 \%$ from the cancerous. This observation suggested that hyaluronidases were not tightly bound to the tissue or the cells. By comparing the total hyaluronidase activity in healthy colon, and in macroscopically normal and cancerous specimens of colorectal carcinoma samples, it was found to be elevated up to $100 \%$ in cancerous specimens compared to both others.

Statistical analysis of the results obtained from hyaluronan zymography revealed that hyaluronidase activity was related to the stage and grade of cancer. Specifically, at early stages high hyaluronidase activity was observed, and after stage B2 the enzymatic activity declined, however it increased at very late stages. These results implied that hyaluronidases in the onset of pathological conditions tended to create small fragments of hyaluronan that help tumor progression. It would be interesting to identify the size distribution of hyaluronan at early stages of cancer, since it is well reported that hyaluronan of small molecular mass is present in cancer [31,32].

On the other hand, high molecular mass hyaluronan induces tissue hydration and therefore it physically creates spaces through which tumor cells migrate and invade, and this might be the explanation of the decreased hyaluronidase activity after the early stages. The increase of the activity at late stages of cancer may be required for the final degradation and the removal of the ECM components sensitive to the enzyme. Of course, it is not only hyaluronidases activity, but hyaluronan synthases activity that plays also important role in hyaluronan size and therefore in tumor progression and this is another point of inerest. A third point requiring clarification is concerning to the presence of highly expressing CD44 cells, being an additional significant factor related to hyaluronan that affects tumor progression.

As far as it concerns the grade of cancer it seemed that there was no significant differences neither between macroscopically normal samples of poor, moderately and well differentiated specimens nor between cancerous ones. Nevertheless, cancerous specimens contained $50-80 \%$ more hyaluronidase activity than macroscopically normal.

Using Western Blotting analysis, we managed to clear up the involvement of individual hyaluronidases existing in certain parts of the tissue; normal and cancerous. The hyaluronidases existing in samples were Hyal-1, -2 , -3 and PH-20. It seemed that at early stages of tumor growth $\mathrm{PH}-20$ was the most abundant extracellularly, as it was extracted mainly with PBS. At advanced stages it seemed that Hyal-1, -2 and $\mathrm{PH}-20$ had a collaborating action for fragmention of hyaluronan. The above hyaluronidases didn't act just extracellularly, but also had a transmembrane action, since they appeared in PBS and $4 \mathrm{M} \mathrm{GdnHCl}$ extracts. The late stages of cancer ( $\mathrm{C} 2$ and $\mathrm{D}$ ) seemed to prefer mostly the synergistic action of Hyal-1, PH-20 and Hyal-3. The last one seemed to be localized entirely in cell membrane as it was present only in $4 \mathrm{M}$ GdnHCl-1\% Triton X-100 extracts. However, it remained unclear at what point the fragmentation of hyaluronan switched from an extracellular or cell surface process to an endosomal or lysosomal process and might be due to the energy demands of the cancer cells. In addition, the factors regulating the differential expression of hyaluronidase isoforms are not known, although it has been proposed growth factors may have such effect [33] and Hyal-1 is regulated epigenetically [34].

\section{Conclusions}

The metabolic pathways for hyaluronan degradation are highly ordered, composed of carefully controlled reactions that rely on regulation of individual enzyme activities. From our work hyaluronidases seemed to play different tissue distribution role in colon cancer, with a combining action of these isoenzymes in colon cancer progression. Understanding the mechanisms of hyaluronidases involved in colon cancer progression may be a useful tool for future prognosis of colon cancer. However, how such regulation and mechanisms are accomplished needs to be clarified.

\section{Author details}

${ }^{1}$ Laboratory of Biochemistry, Department of Chemistry, University of Patras, Patras, Greece. ${ }^{2}$ Department of Surgery, University Hospital, Patras, Greece. ${ }^{3}$ Laboratory of Biological Chemistry, Department of Medicine, University of Patras, Patras, Greece.

\section{Authors' contributions}

$H B$, IT and DHV carried out RT-PCR analysis, western blotting and data analysis, participated in the study design and drafted the manuscript. DB, DK and MSS participated in the collection and characterization of patiens' samples. NP and DAT conceived of the study and participated in its design and coordination. All authors read and approved the final manuscript.

\section{Competing interests}

The authors declare that they have no competing interests.

Received: 10 December 2009 Accepted: 17 September 2010 Published: 17 September 2010

\section{References}

1. Stern $R$, Asari AA, Sugahara KN: Hyaluronan fragments: an informationrich system. Eur J Cell Biol 2006, 85:699-715.

2. Weigel P, Hascall VC, Tammi M: Hyaluronan synthases. J Biol Chem 1997, 272:13997-14000. 
3. DeAngelis $P$ : Hyaluronan synthases: fascinating glycosyltransferases from vertebrates, bacterial pathogens, and algal viruses. Cell Mol Life Sci 1999, 56:670-682.

4. Evanko $\mathrm{S}$, Tammi M, Tammi R, Wight $\mathrm{T}$ : Hyaluronan-dependent pericellular matrix. Adv Drug Deliv Rev 2007, 59:1351-1365.

5. Itano N: Simple primary structure, complex turnover regulation and multiple roles of hyaluronan. J Biochem 2008, 144:131-137.

6. Toole B: Hyaluronan: from extracellular glue to pericellular cue. Nature Rev Cancer 2004, 4:528-539.

7. Menzel E, Farr C: Hyaluronidase and its substrate hyaluronan: biochemistry, biological activities and therapeutic uses. Cancer Lett 1998, 131:3-11.

8. Turley $E$, Noble $P$, Bourguignon $L$ : Signaling properties of hyaluronan receptors. J Biol Chem 2002, 277:4589-4592.

9. Koochekpour S, Pilkington G, Merzak A: A Hyaluronic acid/CD44 H interaction induces cell detachment and stimulates migration and invasion of human glioma cells in vitro. Int J Cancer 1995, 63:450-454.

10. Toole B: Glycosaminoglycans in morphogenesis. In Cell Biology of the Extracellular Matrix. Edited by: Hey ED. NY, Plenum Press; 1981:259-294.

11. Stern R, Jedrzejas M: Hyaluronidases: their genomics, structures, and mechanisms of action. Chem Rev 2006, 106:818-839.

12. Csoka A, Frost $G$, Stern $R$ : The six hyaluronidase-like genes in the human and mouse genomes. Matrix Biol 2001, 20:499-508.

13. Lokeshwar V, Rubinowicz D, Schroeder G, Forgacs E, Minna J, Block N: Stromal and epithelial expression of tumor markers hyaluronic acid and HYAL1 hyaluronidase in prostate cancer. J Biol Chem 2001, 276:11922-11932.

14. Franzmann E, Schroeder G, Goodwin W, Weed D, Fisher P, Lokeshwar V: Expression of tumor markers hyaluronic acid and hyaluronidase (HYAL1) in head and neck tumor. Int I Cancer 2003, 106:438-445.

15. Lokeshwar V, Young M, Goudarzi G, lida N, Yudin A, Cherr G: Identification of bladder tumor-derived hyaluronidase: its similarity to HYAL1. Cancer Res 1999, 59:4464-44670.

16. Lokeshwar V, Cerwinka W, Isoyama T, Lokeshwar B: HYAL1 hyaluronidase in prostate cancer: a tumor promoter and suppressor. Cancer Res 2005, 65:7782-7789.

17. Lokeshwar V, Cerwinka W, Lokeshwar B: HYAL1 hyaluronidase: a molecular determinant of bladder tumor growth and invasion. Cancer Res 2005, 65:2243-2250.

18. Udabage L, Brownlee G, Nilsson S, Brown T: The over-expression of HAS2, Hyal-2 and CD44 is implicated in the invasiveness of breast cancer. Exp Cell Res 2005, 310:205-217.

19. Junker $N$, Latini S, Peterson L, Kristjansen P: Expression and regulation patterns of hyaluronidases in small cell lung cancer and glioma lines. Oncol Rep 2003, 10:609-644.

20. Ropponen K, Tammi M, Parkkinen J, Eskelinen M, Tammi R, Lipponen P, Agren U, Alhava E, Kosma V: Tumor cell-associated hyaluronan as an unfavourable prognostic factor in colorectal cancer. Cancer Res 1998, 58:342-347.

21. Skandalis SS, Theocharis DA, Papageorgakopoulou N, Vynios DH: The extractability of extracellular matrix components as a marker of cartilage remodeling in laryngeal squamous cell carcinoma. Biochim Biophys Acta 2005, 1721:81-88.

22. Papageorgakopoulou N, Vynios DH, Karayanni K, Maras A Papapetropoulou M: Electrophoretic analysis of hydrolytic enzymes of Escherichia coli cells starved in seawater and drinking water: comparison of gelatinolytic, caseinolytic, phosphohydrolytic and hyaluronolytic activities. Microbiol Res 1997, 152:299-305.

23. Tsilemou A, Assouti M, Papageorgakopoulou N, Karamanos NK, Tsiganos CP, Vynios DH: The presence of a novel extracellular hyaluronidase in squid cranial cartilage. Biochimie 2004, 86:579-586.

24. Christopoulos TA, Papageorgakopoulou N, Theocharis DA, Mastronikolis N, Papadas TA, Vynios DH: Hyaluronidase and CD44 hyaluronan receptor expression in squamous cell laryngeal carcinoma. Biochim Biophys Acta 2006, 1760:1039-1045.

25. Laemmli UK: Cleavage of structural proteins during the assembly of the head of bacteriophage T4. Nature 1970, 227:680-685.

26. Heldin P: Importance of hyaluronan biosynthesis and degradation in cell differentiation and tumor formation. Brazilian J Med Biol Res 2003, 36:967-973.
27. Paiva P, Damme M, Tellbach M, Jones R, Jobling T, Salamonsen L: Expression patterns of hyaluronan, hyaluronan synthases and hyaluronidases indicate a role for hyaluronan in the progression of endometrial cancer. Gynecol Oncol 2005, 98:193-202.

28. Wang F, Grigorieva EV, Li J, Senchenko VN, Pavlova TV, Anedchenko EA, Kudryavtseva AV, Tsimanis A, Angeloni D, Lerman MI, Kashuba VI, Klein G, Zabarovsky ER: HYAL1 and HYAL2 inhibit tumour growth in vivo but not in vitro. PLOS One 2008, 3:e3031.

29. Nykopp TK, Rilla K, Sironen $\mathrm{R}$, Tammi Ml, Tammi RH, Hämäläinen $\mathrm{K}$, Heikkinen AM, Komulainen M, Kosma VM, Anttila M: Expression of hyaluronan synthases (HAS1-3) and hyaluronidases (HYAL1-2) in serous ovarian carcinomas: inverse correlation between HYAL1 and hyaluronan content. BMC Cancer 2009, 9:143.

30. Kramer MW, Golshani R, Merseburger AS, Knapp J, Garcia A, Hennenlotter J, Duncan RC, Soloway MS, Jorda M, Kuczyk MA, Stenzl A, Lokeshwar VB: HYAL-1 hyaluronidase: a potential prognostic indicator for progression to muscle invasion and recurrence in bladder cancer. Eur Urol 2010 57:86-93.

31. Kumar S, West D, Ponting J, Gattamaneni H: Sera of children with renal tumours contain lowmolecular- mass hyaluronic acid. Int J Cancer 1989, 44:445-448.

32. Lokeshwar V, Oebek C, Soloway M, Block N: Tumor-associated hyaluronic acid: a new sensitive and specific urine marker for bladder cancer. Cancer Res 1997, 57:773-777.

33. Berdiaki A, Nikitovic D, Tsatsakis A, Katonis P, Karamanos NK, Tzanakakis GN: bFGF induces changes in hyaluronan synthase and hyaluronidase isoform expression and modulates the migration capacity of fibrosarcoma cells. Biochim Biophys Acta 2009, 1790:1258-1265.

34. Lokeshwar VB, Gomez P, Kramer M, Knapp J, McCornack MA, Lopez LE, Fregien N, Dhir N, Scherer S, Klumpp DJ, Manoharan M, Soloway MS, Lokeshwar BL: Epigenetic regulation of HYAL-1 hyaluronidase expression. identification of HYAL-1 promoter. J Biol Chem 2008, 283:29215-29227.

\section{Pre-publication history}

The pre-publication history for this paper can be accessed here: http://www.biomedcentral.com/1471-2407/10/499/prepub

\section{doi:10.1186/1471-2407-10-499}

Cite this article as: Bouga et al: Involvement of hyaluronidases in colorectal cancer. BMC Cancer 2010 10:499.

\section{Submit your next manuscript to BioMed Central and take full advantage of:}

- Convenient online submission

- Thorough peer review

- No space constraints or color figure charges

- Immediate publication on acceptance

- Inclusion in PubMed, CAS, Scopus and Google Scholar

- Research which is freely available for redistribution

Submit your manuscript at www.biomedcentral.com/submit
Ciomed Central 